\title{
A Review on Treatment of Aquaculture Wastes
}

\author{
Hong $\mathrm{Xu}^{1, \mathrm{a}}$, Shaohong $\mathrm{You}^{2, \mathrm{~b}}$ \\ ${ }^{1}$ Guangxi Key Laboratory of Environmental Pollution Control Theory and Technology, Guilin \\ University of Technology, Guilin 541004, China; \\ ${ }^{2}$ Guangxi Collaborative Innovation Center for Water Pollution Control and Water Safety in Karst \\ Area, Guilin University of Technology, Guilin 541004, China \\ a1015191577@qq.com, b646761963@qq.com
}

Keywords: aquaculture, wastewater, bioremediation

\begin{abstract}
This paper mainly summarizes the current situation of aquaculture and biological treatment technology, and summarizes the application of water treatment process and biological engineering in aquaculture wastewater treatment. Pointing that using the biochemical reaction characteristics of microbial in the purification of water quality to establish a variety of biological systems will have great research value and broad market prospects.
\end{abstract}

\section{Introduction}

China has the largest fishery industry in terms of total aquatic production and export since 1990. Both freshwater aquaculture and mariculture have lack of management. Most of aquaculture wastewater was discharged directly without treatment and it may cause great damage to receiving water. The nitrogen-containing compound waste was considered to be main contaminant of aquaculture. Ammonia is the main nitrogen-containing compound.

\section{Phytoremediation}

\subsection{Constructed wetland}

Constructed wetland is a kind of sewage ecological treatment engineering technology combined environmental and wastewater treatment. Water treatment system structure of wetland can be divided into three types: artificial surface flow, subsurface horizontal flow and vertical flow type. In the practical application, it can also use the compound constructed wetland.

Plants in constructed wetlands play a key role in the purification of water quality. Many domestic scholars have studied a large number of plants, trying to find a high efficient plant in removal of organic matter, nitrogen, phosphorus, COD and other contaminants. The process of wastewater flowing through the wetland can effectively deal with the ammonia nitrogen and nitrite, but is lack of effective treatment of nitrate and phosphorus [1]. Ammonia nitrogen requires long residence time to remove. However, the constructed wetland needs a large area of land and is vulnerable to pests and diseases limiting its own development and practical application.

\subsection{Algae}

One of the cleaning organisms, the large algae can transform the nutrients in the wastewater into valuable commodities (such as feed, medicinal materials, commodities, etc.). Wang et al added $\mathrm{U}$. pertusa to the shrimp aquaculture water and the result showed that U. pertusa can efficiently convert water nitrogen and phosphorus compounds without oxygen [2]. Algae can reduce the water pollution, but also can be used to degrade the organic waste in discharged wastewater. Huang by a large number of algae on nitrogen and phosphorus removal experiment, concluded that C. vulgaris is most suitable for sewage treatment of the algae, that its nitrogen and phosphorus removal rate reached above $80 \%$ and that nitrogen and phosphorus removal rate were respectively as high as $90 \%$ when mixed with activated sludge [3]. 


\section{Microbial remediation}

\subsection{Activated sludge method}

Activated sludge method is one of the main technologies of wastewater biological treatment technology and its nitrogen and phosphorus removal rate are high. For the treatment of wastewater, adding nitrification and denitrification bacteria which can form larger zoogloea to absorb and decompose the target pollutants. Nugul et al have used SBR combined with activated sludge process for treating marine aquaculture wastewater and studied the effect of salinity on the operation. The result showed that the low salinity had an optimistic affection on denitrification [4].

\subsection{Biological membrane method}

Biological membrane method has the advantages of simple operation and high efficiency. Its filter material surface area provides a good place for microbial growth and reproduction. Microorganisms attached to the surface of the filler, and this way of adsorption and degradation of organic matter in the water, compared with the activated sludge process, which is equivalent to the fixed effect of the microorganism, and does not appear to have sludge expansion problem. Gelatin mucosal biofilm formed on the surface of filter can effectively reduce the turbidity, nitrogen and hydrogen sulfide content of wastewater while reduce COD and inhibit the growth of harmful microorganisms.

The common aquaculture wastewater biofilm treatment system usually includes UV sterilizer, ozone generator, protein separator and biological filter. Generally, the bio-filter is a carrier which microbial can form biofilm on and make suspension growth $[5,6]$. Intensive cultivation system usually adopt submerged biological filter, drop filter, rotating biological contactor and fluidized bed for itself wastewater treatment.

\subsection{High-efficient bacterial}

The high efficiency, environmental friendly and economically viable microbiological treatment technology requires a comprehensive understanding of all microorganisms involved in the every process of biological filter [7]. In aquaculture, photosynthetic bacteria can degrade toxic substances such as nitrite, hydrogen sulfide, and increase the dissolved oxygen content of water and improve water transparency, and can be used as feed and feed additives. Domestic and foreign researches on the application of microorganism in aquaculture are mainly focused on the research on the inhibition of the pathogenic bacteria and the degradation of organic matter. Zhang et al studied the effect of R. acidophila, R. spheroids and T. roseopersicina on the growth of A. hydrophila and A. caviae. The result showed that all the three photosynthetic bacteria had obvious inhibitory effect on those two pathogens [8]. Huang et al also found that the removal rate of ammonia nitrogen in the landscape water of Southwestern University was 95\% [9].

\subsection{Immobilized microorganism technology}

Immobilized microorganism technology is evolved from the immobilized enzyme technology and it is the technology which utilizes physical or chemical methods to limit microbial biomass in fixed space and to maintain a high biological activity. Because it has the characteristics of maintaining high concentration of biomass, high processing load, less sludge production, strong stability and easy control etc., it is soon become one of the most important experimental targets. At present, the method of biological fixation is mainly used in the method of embedding and adsorption. The immobilized carrier cannot make secondary pollution during the treatment processing and must be stable, non-toxic and have strong resistance to water flow, high mass transfer performance, long service life, etc. Common natural polymer gel carrier (agar, sodium alginate, etc.) are easy to be decomposed by anaerobic microbial and anti-impact performance is not as good as the synthesis of polymer gel (polyethylene glycol PEG, polyvinyl alcohol PVA, polyacrylamide ACAM, etc.). PVA is widely used as a carrier for immobilization because of the advantages of high chemical stability, high resistance to mechanical impact strength and low price.

In view of the immobilized strains of aquaculture wastewater treatment, studies are usually focused on the fixed technology of photosynthetic bacteria and nitrification bacteria. Combining 
PVA with photosynthetic bacteria, on one hand, can improve the photosynthetic bacteria purification ability. On the other hand, it also isolates other species and maintains the dominant position at the same time. Yu et al combined Photosynthetic bacteria in PNA to purify pond water and the result showed that ammonia removal rate was above $90 \%$ [10].

\section{Combined control technology of bacteria and algae}

With the development of modern biotechnology, the use of molecular tools can not only evaluate the biological diversity, but also observe the microbial life activities, so that we can better understand the interaction between microbial colonies and optimize the new wastewater treatment process. According to the research of the predecessors, it is known that the types of microorganisms which involve in degrading $\mathrm{TN}, \mathrm{TP}$, ammonia nitrogen, nitrite nitrogen, $\mathrm{COD}$, and their behavior characteristics. There are also a lot of scholars trying to improve the efficiency of wastewater treatment by using these microorganisms.

\section{Prospect}

Aquaculture has been developed rapidly in the past few decades. From the initial pond cultivation to intensive cultivation, a large number of feed, hormones and antibiotics become the main sources of pollution in the aquaculture water. Microbial method is widely used in aquaculture wastewater treatment. With the development of biotechnology and genetic engineering, using the biochemical reaction characteristics of microbial in the purification of water quality to establish a variety of biological systems will have great research value and broad market prospects.

\section{Acknowledgements}

This research was sponsored by the Guangxi Talent Highland for Hazardous Waste Disposal Industrialization, Guangxi Scientific Experiment Center of Mining, Metallurgy and Environment. The authors thank the Guangxi Natural Science Foundation (2011GXNSFF018003 and 2013GXNSFBA019210), Guangxi scientific research and technology development projects (GuiKeGong14124004-3-7), Guangxi Colleges and Universities Key Laboratory of Agricultural Environment and Ecological Security, Guangxi Colleges and Universities Key Laboratory of Heavy Metal Pollution Prevention Theory and Technology. Corresponding author: Shaohong You. Email: 646761963@qq.com.

\section{References}

[1] Sindilariu P-D, Schulz C, Reiter R. Treatment of flow-through trout aquaculture effluents in a constructed wetland. Aquaculture. 270 (2007) 4, pp. 92-104.

[2] Wang Jiqiao, Jin Cuili, Zhang Xin, et al. Experimental polyculture different density of Ulva and China shrimp. Journal of Fisheries. (2001) 1, pp. 32-37.

[3] Huang Kui. Study on mechanism of nitrogen and phosphorus removal of algae. Nanchang University. (2007).

[4] Intrasungkha N, Keller J, Blackall L L. Biological nutrient removal efficiency in treatment of saline wastewater. Water Science and Technology. 39 (1999) 6, pp. 183-190.

[5] Gutierrez-Wing M T, Malone R F. Biological filters in aquaculture: Trends and research directions for freshwater and marine applications. Aquacultural Engineering. 34 (2006) 3, pp. 163-171.

[6] Avnimelech Y. Bio-filters: The need for new comprehensive approach. Aquacultural Engineering. 34 (2006) 3, pp. 172-178. 
[7] Schreier H J, Mirzoyan N, Saito K. Microbial diversity of biological filters in recirculating aquaculture systems. Current Opinion in Biotechnology. 21 (2010) 3, pp. 318-325.

[8] Zhang Xindi, Jin Yefei, Chen Ying. The effect of photosynthetic bacteria on the growth of fish pathogenic bacteria. Chinese Journal of Ecological Agriculture. (2002) 3, pp. 659-663.

[9] Huang Xuejiao, Yang Chong, Luo Yaxue, et al. Research progress of photosynthetic bacteria in the treatment of water pollution. (2014) 3, pp. 119-124.

[10] Yu Peifen, Wang Lihua, war carrying wing. Of photosynthetic bacteria, isolation, identification and immobilized and in application of pond water quality purification. Biotechnology. (1995) 3, pp. $35-44$. 